\title{
ВЛИЯНИЕ ТЕХНОЛОГИИ ПРОТЕЗИРОВАНИЯ ЗУБОВ НА ДИНАМИКУ РАННИХ ПРЕДИКТОРОВ ВОСПАЛИТЕЛЬНО-ДЕСТРУКТИВНОГО ПРОЦЕССА В ПЕРИИМПЛАНТАТНОЙ ЗОНЕ
}

\author{
В. П. Тлустенко, И. М. Байриков, Д. А. Трунин, О. А. Гусякова, С. С. Комлев
}

Самарский государственный медицинский университет, Самара, Россия

\begin{abstract}
Объективная оценка морфофункциональных характеристик состояния мягких тканей и костных структур, прилежащих к дентальному имплантату, позволяет контролировать динамику процессов остеоинтеграции в системе челюсть - дентальный имплантат. Целью работы было исследовать уровни маркеров $\beta$-CrossLaps, C-реактивный белок (СРБ), остеокальцина после ортопедического лечения пациентов с применением усовершенствованных технологий протезирования зубов с опорой на дентальные имплантаты. Провести биохимический анализ ротовой жидкости пациентов после протезирования на дентальных имплантатах и новых разборных дентальных имплантатах. Пациентам основной группы (52 человека) изготовили съемные ортопедические конструкции с металлическим каркасом и фиксирующими элементами с опорой на разборные дентальные имплантаты и съемные ортопедические конструкции с опорой на серийно выпускаемые дентальные имплантаты. Для пациентов контрольной группы (12 человек) были изготовлены съемные ортопедические конструкции из акриловых пластмасс с опорой на дентальные имплантаты, выпускаемые серийно. Всем пациентам через 6 месяцев исследовали уровни маркеров $\beta$-CrossLaps, CPБ, остеокальцина в ротовой жидкости. У пациентов основной группы содержание

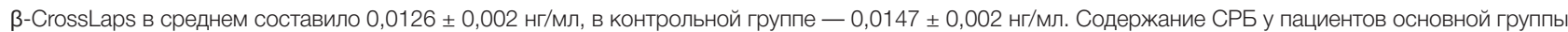

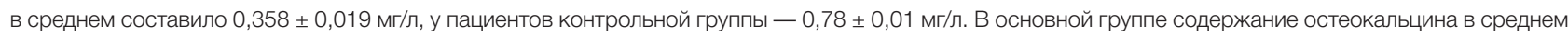

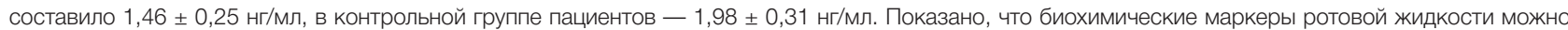
использовать для прогнозирования осложнений после установки дентальных имплантатов. Протезирование усовершенствованными конструкциями на разборных дентальных имплантатах сопряжено с меньшим количеством осложнений.
\end{abstract}

Ключевые слова: съемные ортопедические конструкции, разборный дентальный имплантат, метаболические показатели $\beta$-CrossLaps, CPБ, остеокальцин

Информация о вкладе авторов: В. П. Тлустенко, И. М. Байриков, Д. А. Трунин, С. С. Комлев - разработка концепции и дизайна исследования, хирургическое и ортопедическое лечение пациентов; О. А. Гусякова, И. М. Байриков, С. С. Комлев - сбор и обработка материала, биохимическое исследование ротовой жидкости, статистическая обработка результатов.

Соблюдение этических стандартов: исследование одобрено этическим комитетом Самарского государственного медицинского университета (протокол № 2018/196). Все пациенты подписали информированное согласие на участие в исследовании (проведение операции дентальной имплантации и ортопедическое лечение, сбор образцов ротовой жидкости).

$\bowtie$ Для корреспонденции: Сергей Сергеевич Комлев

ул. Чапаевская, д. 89, г. Самара, 443099; stomat.ks@mail.ru

Статья получена: 27.11.2018 Статья принята к печати: 03.04.2019 Опубликована онлайн: 13.04.2019

DOI: $10.24075 /$ vrgmu.2019.025

\section{INFLUENCE OF DENTAL PROSTHETICS TECHNOLOGY ON THE DYNAMICS OF EARLY PREDICTORS OF DESTRUCTIVE INFLAMMATORY PROCESS IN THE PERIIMPLANT ZONE}

Tlustenko VP, Bayrikov IM, Trunin DA, Gusyakova OA, Komlev SS $\bowtie$

Samara State Medical University, Samara, Russia

An objective assessment of the morphofunctional characteristics of the state of soft tissues and bone structures adjacent to the dental implant allows to control the dynamics of the processes of osseointegration in the jaw-dental implant system. The aim of the work was to investigate the level of the $\beta$-CrossLaps, C-reactive protein (CRP), osteocalcin markers after orthopedic treatment of patients using dental implant supported advanced dental restoration technologies, to perform a biochemical analysis of the oral fluid of patients after restoration using dental implants and new two-part dental implants. In patients of the index group (52 people), the removable prostheses with metal frame and fixing elements or the commercially available dental implant supported removable prostheses were installed. For the patients of the control group (12 people), the commercially available dental implant supported removable prostheses of acrylic plastics were constructed. For all the patients after 6 months the level of $\beta$-CrossLaps, CRP, osteocalcin markers in the oral fluid was analysed. In patients of the index group, the average content of $\beta$-CrossLaps was $0.0126 \pm 0.002 \mathrm{ng} / \mathrm{ml}$, in the control group it was $0.0147 \pm 0.002 \mathrm{ng} / \mathrm{ml}$. The average content of the CRP in patients of the index group was $0.358 \pm 0.019 \mathrm{mg} / \mathrm{l}$, in patients of the control group it was $0.78 \pm 0.01 \mathrm{mg} / \mathrm{l}$. In patients of the index group, the average content of osteocalcin was $1.46 \pm 0.25 \mathrm{ng} / \mathrm{ml}$, in the control group it was $1.98 \pm 0.31 \mathrm{ng} / \mathrm{ml}$. It has been shown that biochemical markers of the oral fluid can be used to predict complications after the dental implants installation. Restoration with two-part dental implants of modern design is associated with fewer complications.

Keywords: removable dental prostheses, two-part dental implant, $\beta$-CrossLaps, CRP, osteocalcin metabolic markers

Author contribution: Tlustenko VP, Bayrikov IM, Trunin DA, Komlev SS - concept and research design, surgical and orthopedic treatment of patients; Gusyakova OA, Bayrikov IM, Komlev SS - collection and processing of material, biochemical analysis of oral fluid, statistical processing of results.

Compliance with ethical standards: the study was approved by the Ethics Committee of Samara State Medical University (protocol № 2018/196). All patients signed a voluntary informed consent to participate in the study (dental implantation and orthopedic treatment, collection of oral fluid samples)

Correspondence should be addressed: Sergey S. Komlev

Chapayevskaya 89, Samara, 443099; stomat.ks@mail.ru

Received: 27.11.2018 Accepted: 03.04.2019 Published online: 13.04.2019

DOI: $10.24075 /$ brsmu.2019.025

При лечении пациентов с частичным и полным отсутствием зубов ортопедическими конструкциями с опорой на дентальные имплантаты важны планирование оперативного вмешательства, выбор имплантационной системы и ортопедической конструкции, прогнозирование исхода избранного комплекса мероприятий. Актуальна объективная оценка морфофункциональных характеристик состояния мягких тканей и костных структур, прилежащих к дентальному имплантату. Она позволяет предотвратить ошибки, которые могут приводить к нарушению процессов 
остеоинтеграции в системе челюсть - дентальный имплантат и способствовать развитию ранних и поздних воспалительно-деструктивных осложнений [1].

После имплантации серийно выпускаемых дентальных имплантатов, разборных дентальных имплантатов и ортопедического лечения усовершенствованными ортопедическими конструкциями необходимо изучать факторы, служащие индикаторами доклинической стадии развития деструктивно-воспалительных нарушений. С этой целью проводят изучение ротовой жидкости как биосреды, обеспечивающей гомеостаз тканей периимплантатной зоны [2-4].

Регенерация костной ткани вокруг имплантата после операции дентальной имплантации представляет собой совокупность процессов структурного и функционального восстановления после повреждения. В основе репарации кости лежат механизмы трансформации недисфреренцированных клеток в остеобласты, процесс остеоиндукции, а также возникновение матрикса, обеспечивающего отложение костного вещества. К показателям, отражающим процессь деструкции и состояние минерализации-деминерализации костной ткани, относятся остеокальцин, С-реактивный белок (СРБ), продукт расщепления С-телопептида коллагена I типа ( $\beta$-CrossLaps) [5-8].

Остеокальцин представляет собой неколлагеновый кальцийсвязывающий белок костного матрикса, состоящий из 49 аминокислотных остатков. Он синтезируется почти исключительно остеобластами и участвует в процессах минерализации, является маркером костного ремоделирования. $\beta$-CrossLaps - маркер резорбции костной ткани. СРБ - классический белок острой фазы воспаления, который рассматривают как наиболее чувствительный лабораторный маркер инфекции, воспаления и тканевого повреждения. По структуре СРБ состоит из пяти идентичных полипептидных субъединиц, образующих циклическую дискообразную пентамерную структуру. Синтез СРБ происходит в гепатоцитах и регулируется провоспалительными цитокинами. На фоне воспаления, инфекции или травматического повреждения уровень СРБ быстро возрастает. В ротовой жидкости после активации его синтеза в гепатоцитах уровень СРБ достигает максимальных значений через 24 ч [9-12].

Осложнения при дентальной имплантации возникают в 6-23\% случаев. По данным эпидемиологических исследований, у пациентов, длительно пользующихся протезами с опорой на дентальные имплантаты, признаки мукозита присутствуют в 80\% наблюдений, а периимплантита - в 28-56\%. Клинические проявления дентального периимплантита обусловлены наличием воспалительно-деструктивного процесса. Значительное число публикаций свидетельствует о большой информативности оценки качественных и количественных показателей ротовой жидкости пациентов, возможности использовать показатели ротовой жидкости с прогностической целью при дентальной имплантации [13-15].

Целью работы было определить уровни маркеров $\beta$-CrossLaps, СРБ, остеокальцина после ортопедического лечения пациентов с применением усовершенствованных технологий протезирования с опорой на дентальные имплантаты.

\section{ПАЦИЕНТЫ И МЕТОДЫ}

В исследование вошли 52 пациента основной и 12 пациентов контрольной групп. Критерии включения пациентов в исследование: любой пол; частичное отсутствие зубов I и || классов по Кеннеди. Критерии исключения: наличие зубочелюстных аномалий; наличие заболеваний эндокринной системы, желудочно-кишечного тракта.

Пациенты основной группы были разделены на две подгруппы: основная группа 1 и основная группа 2. В основную группу 1 вошли 12 пациентов: 4 мужчин и 8 женщин в возрасте 45-65 лет. Пациентам этой группы установили съемные ортопедические конструкции с металлическим каркасом и фиксирующими элементами. Использовали телескопические коронки и замковые крепления. Было установлено 28 разборных дентальных имплантатов нашей конструкции (Патент РФ № 2593349).

В основную группу 2 вошли 40 пациентов: 15 мужчин и 25 женщин в возрасте 45-65 лет. Пациентам этой группы установили съемные ортопедические конструкции с опорой на серийно выпускаемые дентальные имплантаты (85 дентальных имплантатов). Фиксирующие элементы располагались в металлическом каркасе съемного протеза.

Пациентам основной группы изготавливали съемные протезы из термопластов, нейлона с металлическим каркасом (Патент РФ № 2588488). Введение в термопласт литых каркасов позволило равномерно распределить нагрузку на опорные зубы и дентальные имплантаты, получить возможность стабилизации по плоскости, повысить фиксацию протеза.

Контрольную группу составили 12 пациентов: 3 мужчин и 9 женщин в возрасте 45-65 лет, которым были изготовлены съемные ортопедические конструкции из акриловых пластмасс с опорой на дентальные имплантаты, выпускаемые серийно. Фиксирующие элементы располагались в базисе съемной ортопедической конструкции; в зависимости от дефекта зубного ряда устанавливали 2-3 дентальных имплантата.

При обследовании пациентов оценивали стоматологический статус. Всем участникам проводили биохимический анализ образцов ротовой жидкости путем определения метаболических показателей: $\beta$-CrossLaps, СРБ, остеокальцина. Изучение метаболических процессов гомеостаза полости рта представляет собой неинвазивный метод исследования. Оценку метаболических процессов в костной ткани пациентов контрольной и основной групп проводили через 6 месяцев после ортопедического лечения. На этапе биохимического исследования слюны у пациентов не было признаков острых соматических заболеваний.

Определение количественного содержания в составе ротовой жидкости $\beta$-CrossLaps и остеокальцина осуществляли твердофазным пробирочным методом в электрохемилюминесцентной реакции на основе стрептавидин-биотиновой технологии с рутениевой меткой на автоматизированном электрохемилюминесцентном лабораторном комплексе «Elecsys-2010» (F. HoffmannLa Roche; Швейцария). Определение СРБ проводили на биохимическом анализаторе Cobas Integra 400 plus (F. Hoffmann La Roche; Швейцария). Использовали диагностические наборы (F. Hoffmann La Roche; Швейцария): набор калибраторов для определения $\beta$-CrossLaps, N-MID остеокальцина, набор реагентов для количественного определения $\beta$-CrossLaps, N-MID остеокальцина, C-реактивный белок LX.

Статистическую обработку полученных данных проводили с использованием $t$-критерия Стьюдента на персональном компьютере под управлением операционной 
системы Microsoft Windows 10 с применением статистического пакета SPSS Statistics 21.0 (лицензия № 20130626-3; США).

Применяли параметрический $t$-критерий Стьюдента, а также непараметрический дисперсионный анализ Краскела-Уоллиса и тест Манна-Уитни.

\section{РЕЗУЛЬТАТЫ ИССЛЕДОВАНИЯ}

В таблице представлены значения метаболических показателей образцов ротовой жидкости у пациентов контрольной и основной групп через 6 месяцев после ортопедического лечения.

В основной группе содержание $\beta$-CrossLaps в ротовой жидкости в среднем составило 0,0126 \pm 0,002 нг/мл, в контрольной группе - 0,0147 \pm 0,002 нг/мл. В процессе резорбции костной ткани телопептиды с остатками молекул коллагена попадают в ротовую жидкость.

Содержание СРБ в ротовой жидкости у пациентов основной группы в среднем составило 0,358 \pm 0,019 мг/л, у пациентов контрольной группы - 0,78 \pm 0,01 мг/л.

Для оценки метаболических процессов в костной ткани пациентов после проведенного ортопедического лечения нами была проведена оценка содержания остеокальцина в ротовой жидкости. В основной группе оно составило в среднем 1,46 \pm 0,25 нг/мл, в контрольной группе - в среднем 1,98 0,31 нг/мл. Остеокальцин, белок костного матрикса, содержащий у-карбоксиглутаминовую кислоту, способствует фиксации ионов кальция и создает условия для минерализации. Остеокальцин обладает хемотаксическими свойствами по отношению к клеткампредшественницам остеобластов и остеокластов, привлекая их в зону остеогенеза.

В основной группе биохимические показатели у 3 пациентов имели следующие значения: $\beta$-CrossLaps $0,0295 \pm 0,002$ нг/мл, СРБ - 1,17 $\pm 0,03 \mathrm{мг/л,}$ остеокальцина - 2,92 0,11 нг/мл. В контрольной группе у 3 пациентов значения составили: $\beta$-CrossLaps - 0,0463 \pm 0,002 нг/мл, СРБ - 1,49 \pm 0,01 мг/л, остеокальцина 3,11 \pm 0,17 нг/мл. Полученные результаты значений метаболических показателей пациентов контрольной группы свидетельствуют о деструктивных процессах в костной ткани, характерных для периимплантита. Количество осложнений в основной и контрольной группах пациентов составило 5,8 и 16,7\% соответственно.

\section{ОБСУЖДЕНИЕ РЕЗУЛЬТАТОВ}

Состояние гомеостаза полости рта после операции дентальной имплантации изучали путем определения показателей метаболизма ротовой жидкости пациентов контрольной и основной групп, отражающих наличие процессов деструкции, состояние минерализации и деминерализации костной ткани. Исследование ранних предикторов [2, 6, 11] воспалительно-деструктивного процесса в периимплантатной зоне позволяет осуществлять контроль динамики процессов остеоинтеграции в системе челюсть - дентальный имплантат. Метаболические показатели $\beta$-CrossLaps, CРБ, остеокальцина отражали интенсивность воспалительной реакции, характерную для травматического процесса при операции дентальной имплантации.

Анализ СРБ представляется объективным методом скрининга активности воспалительного процесса у пациентов контрольной и основной групп после проведения дентальной имплантации с использованием серийно выпускаемых дентальных имплантатов, разборных дентальных имплантатов и проведенного ортопедического лечения с использованием усовершенствованных ортопедических конструкций.

Для оценки метаболических процессов в костной ткани пациентов после операции дентальной имплантации нами была проведена оценка содержания остеокальцина.

Метод изучения ротовой жидкости как основной гомеостатической среды полости рта объективно отразил реакцию тканей полости рта при воспалительнодеструктивных процессах, которые возникали у пациентов контрольной и основной групп после проведения операции дентальной имплантации. При наличии незначительных воспалительных явлений происходили изменения метаболических показателей ротовой жидкости, связанные с поступлением фрагментов деструкции белковых макромолекул, недоокисленных продуктов обмена.

Увеличение уровня остеокальцина в ротовой жидкости свидетельствовало о снижении минерализации в периимплантатной зоне и пластических ресурсов костной ткани у пациентов контрольной группы. Повышенное содержание СРБ отражает выраженность воспалительной реакции, что позволило получить дополнительные оценочные критерии для характеристики патологического процесса. У пациентов контрольной группы через 3 месяца противовоспалительной и антимикробной терапии произошло снижение уровня биохимических показателей.

Более низкие уровни показателей воспаления у пациентов основной группы по сравнению с контрольной мы связываем с использованием усовершенствованных ортопедических конструкций и фиксирующих элементов с опорой на титановые абатменты разборных дентальных имплантатов.

При анализе результатов содержания белков остеоматрикса в слюне установлено резкое увеличение фрагментов распада $\beta$-CrossLaps и рост концентрации остеокальцина и СРБ. Эти данные свидетельствуют о специфике выявленных нарушений биохимического состава ротовой жидкости при ускорении остекластических процессов у пациентов с осложнениями.

Таблица 1. Метаболические показатели $\beta$-CrossLaps, CPБ, остеокальцина у пациентов контрольной и основной групп через 6 месяцев после дентальной имплантации

\begin{tabular}{|c|c|c|c|c|}
\hline \multirow{2}{*}{ Параметры } & \multirow{2}{*}{ Референсные значения } & \multicolumn{2}{|c|}{ Основная группа } & \multirow{2}{*}{ Контрольная группа } \\
\cline { 3 - 4 } & & 1 & 2 & $0,0147 \pm 0,002$ \\
\hline B-CrossLaps (нг/мл) & $0,01 \pm 0,001$ & $0,0123 \pm 0,002^{*}$ & $0,0128 \pm 0,002^{*}$ & $0,78 \pm 0,01$ \\
\hline СРБ (мг/л) & $0,1 \pm 0,001$ & $0,241 \pm 0,013^{*}$ & $0,476 \pm 0,024^{*}$ & $1,98 \pm 0,31$ \\
\hline Остеокальцин (нг/мл) & $1,11 \pm 0,11$ & $1,33 \pm 0,26^{*}$ & $1,58 \pm 0,24$ & 0 \\
\hline
\end{tabular}

Примечание: * - достоверность различий по сравнению с данными лиц контрольной группы $(p<0,05)$. 
Характерным показателем усиленной резорбции костной ткани является установленное увеличение содержания фрагментов коллагена ( $\beta$-CrossLaps), остеокальцина, СРБ.

\section{ВЫВОДЫ}

Результаты наших исследований подтвердили, что такие метаболические показатели, как $\beta$-CrossLaps, СРБ, остеокальцин, у пациентов после дентальной имплантации информативны относительно прогнозирования осложнений при использовании различных видов дентальных имплантатов. Более низкий процент осложнений и меньшее отклонение от нормы уровня показателей воспаления у пациентов основной группы по сравнению с контрольной предположительно связаны с использованием усовершенствованных ортопедических конструкций и фиксирующих элементов с опорой на титановые абатменты разборных дентальных имплантатов.

\section{Литература}

1. Aziz S. Hard and soft tissue surgical complications in dental implantology. Oral Maxillofac. Surg Clin North Am. 2015; 27 (2): 313-8.

2. Guobis Z, Pacauskiene I, Astramskaite I. General diseases influence on peri-implantitis development: a systematic review. $J$ Oral Maxillofac Res. 2016; 7 (5): 9-14.

3. Lohmann $\mathrm{CH}$, Rampal S, Lohrengel M, Singh G. Imaging in periprosthetic assessment: an orthopaedic perspective. EFORT Open Rev. 2017: 2 (5): 117-25.

4. Greenstein G, Carpentieri J, Cavallaro J. Nerve damage related to implant dentistry: incidence, diagnosis, and management. Compend Contin Educ Dent. 2015; 36 (9): 652-9.

5. Alikhasi M, Alsharbaty MHM, Moharrami M. Digital Implant Impression Technique Accuracy: A Systematic Review. Implant Dent. 2017; 26 (6): 929-35. DOI: 10.1097/ID.0000000000000683.

6. Атрушкевич В. Г., Школьная К. Д. Особенности минерального и костного обмена у пациентов в зависимости от характера течения пародонтита. Лечение и профилактика. 2017; 2 (22): 85-92.

7. Alrabeah GO, Brett P, Knowles JC, Petridis H. The effect of metal ions released from different dental implant-abutment couples on osteoblast function and secretion of bone resorbing mediators. Dent. 2017; 66: 91-101. DOI: 10.1016/j.jdent.2017.08.002.

8. Boronat-Catala M, Catala-Pizarro M, Bagan Sebastian J. Salivary and crevicular fluid interleukins in gingivitis. J Clin Exp Dent. 2014; 6 (1): 175-9.

\section{References}

1. Aziz S. Hard and soft tissue surgical complications in dental implantology. Oral Maxillofac. Surg Clin North Am. 2015; 27 (2): 313-8.

2. Guobis Z, Pacauskiene I, Astramskaite I. General diseases influence on peri-implantitis development: a systematic review. Oral Maxillofac Res. 2016; 7 (5): 9-14

3. Lohmann $\mathrm{CH}$, Rampal S, Lohrengel M, Singh G. Imaging in periprosthetic assessment: an orthopaedic perspective. EFORT Open Rev. 2017: 2 (5): 117-25.

4. Greenstein G, Carpentieri J, Cavallaro J. Nerve damage related to implant dentistry: incidence, diagnosis, and management. Compend Contin Educ Dent. 2015; 36 (9): 652-9.

5. Alikhasi M, Alsharbaty MHM, Moharrami M. Digital Implant Impression Technique Accuracy: A Systematic Review. Implant Dent. 2017; 26 (6): 929-35. DOI: 10.1097/ID.0000000000000683.

6. Atrushkevich VG, Shkolnaya KD. Osobennosti mineral'nogo kostnogo obmena u pacientov $v$ zavisimosti ot haraktera techenija parodontita. Lechenie i profilaktika. 2017; 2 (22): 85-92.

7. Alrabeah GO, Brett P, Knowles JC, Petridis H. The effect of metal ions released from different dental implant-abutment couples on osteoblast function and secretion of bone resorbing mediators. J Dent. 2017; 66: 91-101. DOI: 10.1016/j.jdent.2017.08.002.

8. Boronat-Catala M, Catala-Pizarro M, Bagan Sebastian J. Salivary and crevicular fluid interleukins in gingivitis. J Clin Exp Dent. 2014; $6(1): 175-9$.

9. Casado PL, Aguiar DP, Costa LC. Different contribution of BRINP3 gene in chronic periodontitis and periimplantitis: a cross-sectional study. BMC Oral. Health. 2015; (15): 33. DOI 10.1186/s12903015-0018-6.

10. Plyuhin DV. Soderzhanie produktov svobodnoradikal'nogo okislenija v kostnoj tkani i ishod dental'noj implantacii. Medicinskaja nauka i obrazovanie Urala. 2016; 1 (85): 105-7.

11. Kozlova MV, Mkrtumyan AM, Belyakova AS. Reguljacija metabolicheskih processov kosti pri dental'noj implantacii. Kremlevskaja medicina. Klinicheskij vestnik. 2018; (2): 30-9.

12. Riega-Torres JC, Villarreal-Gonzalez AJ, Ceceñas-Falcon LÁ, Salas-Alanis JC. Sjögren's syndrome (SS), a review of the subject and saliva as a diagnostic method. Gac Med Mex. 2016; 152 (3): 371-80

13. Modi A, Morou-Bermudez E, Vergara J, et al. Validation of two point-of-care tests against standard lab measures of $\mathrm{NO}$ in saliva and in serum. Nitric Oxide. 2017; (64): 16-21. DOI: 10.1016/j. niox.2017.01.009.

14. Alkan EA, Tüter G, Parlar A, et al. Evaluation of peri-implant crevicular fluid prostaglandin levels in augmented extraction sockets by different biomaterials. Acta Odontol Scand. 2016; 74 (7): 532-8.

15. Fernandes $\mathrm{MH}$, Gomes PS. Bone Cells Dynamics during PeriImplantitis: a Theoretical Analysis. J Oral Maxillofac Res. 2016; 7 (3): e6. 